Article

\title{
Direct and Indirect Effects of Social Support and School Social Capital on the Academic Success of 11-19-Year-Old Students Using Distance Learning
}

\author{
Brigita Mieziene 1,*, Arunas Emeljanovas ${ }^{1}$, Roma Jusiene ${ }^{2} \mathbb{D}$, Rima Breidokiene ${ }^{2}$, Sigita Girdzijauskiene ${ }^{2}$, \\ Stanislav Sabaliauskas ${ }^{1}$, Jolita Buzaityte-Kasalyniene ${ }^{2}$, Virginija Budiene ${ }^{1}$, Indre Eiliakaite ${ }^{1}$, \\ Erika Speicyte-Ruschhoff ${ }^{2}$, Edita Babkovskiene ${ }^{1}$, Dainius Zvirdauskas ${ }^{1}$ and Ichiro Kawachi ${ }^{3}$ \\ check for \\ updates \\ 1 Faculty of Medicine, Vilnius University, 01513 Vilnius, Lithuania; arunas.emeljanovas@mf.vu.lt (A.E.); \\ stanislav.sabaliauskas@mf.vu.lt (S.S.); virginija.budiene@gmail.com (V.B.); eiliakaite.indre@gmail.com (I.E.); \\ amapole@gmail.com (E.B.); dainiuszv@gmail.com (D.Z.) \\ 2 Faculty of Philosophy, Vilnius University, 01513 Vilnius, Lithuania; roma.jusiene@fsf.vu.lt (R.J.); \\ r.breidokiene@gmail.com (R.B.); sigita.girdzijauskiene@fsf.vu.lt (S.G.); jolita.kasalyniene@fsf.vu.lt (J.B.-K.); \\ erika.speicyte@gmail.com (E.S.-R.) \\ 3 Department of Social and Behavioral Sciences, Harvard T.H. Chan School of Public Health, Boston, MA 02115, \\ USA; ikawachi@hsph.harvard.edu \\ * Correspondence: brigita.mieziene@mf.vu.lt; Tel.: +37-0-6868-4622
}

Citation: Mieziene, B.; Emeljanovas,

A.; Jusiene, R.; Breidokiene, R.;

Girdzijauskiene, S.; Sabaliauskas, S.; Buzaityte-Kasalyniene, J.; Budiene, V.; Eiliakaite, I.; Speicyte-Ruschhoff, E.; et al. Direct and Indirect Effects of Social Support and School Social Capital on the Academic Success of 11-19-Year-Old Students Using Distance Learning. Sustainability 2022, 14, 2131. https://doi.org/10.3390/ su14042131

Academic Editors: Arantzazu Rodríguez-Fernández, Arantza Fernández-Zabala and Eider Goñi-Palacios

Received: 30 December 2021 Accepted: 10 February 2022 Published: 13 February 2022

Publisher's Note: MDPI stays neutral with regard to jurisdictional claims in published maps and institutional affiliations.

Copyright: (c) 2022 by the authors. Licensee MDPI, Basel, Switzerland. This article is an open access article distributed under the terms and conditions of the Creative Commons Attribution (CC BY) license (https:/ / creativecommons.org/licenses/by/ $4.0 /)$.

\begin{abstract}
In the context of current changes in the education process due to the pandemic, the main aims of this study were to highlight social capital factors within the school community that are associated with better students' outcomes in the context of distance learning. This study was a cross-sectional population-based study. The research sample consisted of 1483 students, whose ages varied from 11 to 19 years old (56.9\% were girls). Academic success in this study was measured in terms of average grade and students' perception of their learning process or outcomes by six single items. A Five-item WHO-5 questionnaire was used to measure students' psychological well-being. Social capital was measured in terms of relationship, trust, reciprocity, and communication within different social contexts in the school community in total by 16 items. School social capital and social support scales were developed from these items. Students' gender and age were also taken into consideration. The research results show that although social capital from parents and peers also matters, the relationship with teachers emerges as the main and the most important resource in supporting positive attitudes and outcomes in to learning (std. $\beta$ varied from 0.116 to 0.439 ). The results also show that higher psychological wellbeing is associated with higher perceived school social capital (std. $\beta$ 0.260) and social support (std. $\beta$ 0.326) and mediates the effects of the latter two for better academic success outcomes. The findings also highlight the importance of close and trusting social ties, especially between students and their teachers as well as parents for better learning outcomes in times of crises and in the context of distance learning. The study results prove that social support and social capital at school are essential factors for sustainable psychological development. The results presumably support the idea that the school is sustainable if it is developing as an ecosystem not solely aimed at academic outcomes. The results of the current study may aid policymakers and practitioners in developing interventions, policies and practices that focus resources where they will have the greatest benefit.
\end{abstract}

Keywords: relationship with teachers; learning motivation; psychological well-being

\section{Introduction}

The COVID-19 pandemic has effected a change in the process of education at school. Schools in Lithuania, as in many other countries, were closed in Spring and Autumn of 2020 and again in Spring of 2021. School closures, in general, affect various areas of per-sonal, 
social, and public life, as well as contributing to social, economic, and health ine-qualities, especially in low-income countries [1]. Any changes in provision to vulnerable groups pose or exacerbate the threat of psychosocial risks and educational gaps, especial-ly in the context of pre-existing psychosocial risks. The authors reviewed the consequences of the COVID-19 pandemic and found that due to school closures, there are negative changes in students' eating habits and decreased physical activity, given that a school is a key place for students to receive healthy food and be physically active during physical education classes, recess and after school. An increase in cases of depression, psychological dis-tress, insomnia, attention deficit disorders was observed. Moreover, restricting social contacts impairs students' social development [2]. Researchers have calculated that due to school closures, students learn only 37 to 50 percent of what they would have learned by attending school [3]. Previous experiences of school closures, prior to the COVID-19 pandemic, due, for example to natural disasters have shown negative consequences for student academic success. Lower learning outcomes are more common in the students who have taken longer to return to the learning process after the disaster [4]. Researchers are already predicting the deterioration in learning outcomes and the associated financial costs to governments $[5,6]$.

The effectiveness of problem management in a given situation is key in the reduction of negative consequences. As success in COVID-19-related problem management differs across schools, it could be assumed that there are school-level factors that facilitate or disrupt the educational process during changes. Here, the social capital resources of the school community (all the participants in the educational process) are highlighted. Social capital includes resources within the social environment, social ties, belonging, social organization, social cohesion, cooperation, tolerance, trust, social support, and norms of social cooperation in a variety of social contexts [7], which are important for learning outcomes and the reduction of psychosocial risks in the educational process in general and in the event of a crisis. During the COVID-19 pandemic, the rapid reorientation of the educational process to distance, mixed or hybrid learning approaches, revealed the importance not only of technical support but also of the school community's ability to accept challenges, solve problems, for the continuity of the educational process. Research conducted at the beginning of the COVID-19 pandemic revealed a need for school community mobilization [8]. The UNICEF report confirms that children with a greater sense of belonging to school have better academic performance [9]. The school is a potentially powerful institution. It has potential access to large community resources that are no less important than financial. Moreover, the National Audit Office revealed that growing funding for education and changes in funding did not have a significant positive impact on student achievement [10].

It has not yet been revealed how social capital, by compensating for or interacting with psycho-social risks, is associated with learning outcomes in a period of crisis. This may be important in other periods of similar global or local change. Studies before COVID-19 have shown that higher social capital was associated with greater satisfaction with the distance learning process and better grades for university students [11] and is generally necessary for academic success [12]. Pre-pandemic studies also showed that higher social capital in its different contexts (family, neighborhood, school, and peer) in the Lithuanian school student population is associated with better academic achievements [13], lower student psychological distress [14], and better self-rated health [13].

It has already been empirically confirmed that there is a strong direct link between perceived social support and students' well-being, assuming that social support reduces risks for mental health among youth [15]. Psychological well-being is an empirically wellsupported indicator that represents the state of being active, vigorous, rested, relaxed, having interests, and being in good spirits, and is an indicator of mental health [16].

Firstly, based on the premise, confirmed by a body of research, more socially engaged people are happier; in turn, they are more productive, flexible, and creative, and demonstrate pro-social behavior [17]; we assume that psychological well-being is a mediator between social capital as well as social support and perceived academic success, as the perception of learning outcomes and actual learning results. 
Secondly, social support may play a role as a buffer against life stresses, and as a role in promoting physical and mental health [18]. Mental health conditions account for $16 \%$ of the global burden of disease and injury in people aged 10-19 years [19]. Thus, it may be assumed that social support may promote psychological well-being by protecting from negative mental health outcomes [18]. In turn, the literature suggests that people with high psychological well-being tend to have attributional styles that are more self-enhancing and more enabling than those low in subjective well-being, suggesting that positive emotions can lead to positive cognitions [20], and so can also lead to better-perceived out-comes in diverse areas of functioning and learning among them. Summing up, the premises written above are in line with the Self-determination theory which emphasizes satisfaction for three basic psychological needs-autonomy, competence, and relatedness-that comes from the social environment- the significant others-and further leads to increased motivation for learning and better performance. The presence of favorable environmental conditions that allow satisfaction of these basic needs is a key factor for mental health [21].

One of the main aims of the study is to highlight social capital factors within the school community at the levels of peers, parents/guardians, teachers, and school administration that are associated with better students' outcomes in the context of distance learning.

School students' social capital is created at the interpersonal level in multiple social contexts, like home, school, neighborhood, etc. Within the context of the school community, students collect their social capital from different recourses, like teachers, schoolmates, etc., and accumulate it into the unique phenomena of school social capital which further is assumed to affect intrapersonal level factors [22]. Based on this premise, another aim of the study is to examine whether social capital potentially increases students' psychological wellbeing and if the latter mediates the relationship between social capital and academic success.

\section{Materials and Methods}

\subsection{Study Design and Procedure}

This is a cross-sectional population-based study based on cluster (area) random sampling. This particular sampling was chosen as the most appropriate in a case when the total area of the research is too large to apply regular random sampling [23]. In Lithuania, in the school year of 2020-2021, the population consisted of 209,600 thousand school children in grades 5th to 12th [24]. The study sample was selected across all 10 regions of Lithuania from May to June 2021. Within each of the ten regions, three schools (primary sampling units) were randomly selected: at least one from the regional centre and one from the rural area. Some of the schools in the country provide education from primary to upper secondary levels, some offers only lower secondary education, others are established as gymnasiums (certain type of secondary schools). The school selection was organized in order to cover both levels of secondary school within each region. In total 33 schools participated in the study. Within each selected school, students from the 5th to 12th grade, one class per grade, were chosen using the classes whose number was followed by the letter A (e.g., 10A). Finally, all students in the selected schools and classes per grade were included in the study, if they had parental consent and agreed to participate themselves. Both the school and classes in the schools were considered clusters. In each selected school, one class per 5 th to 12 th grade was provided with study questionnaires. The questionnaire took approximately $30 \mathrm{~min}$ to complete. The study was conducted in line with the Helsinki Declaration, and the protocol was approved by the Ethics Commit-tee of Vilnius University (No. 66). Researchers obtained the permission of the school administration to collect data. Links to the online questionnaires for students and informed consent for parents were provided by the researchers and sent by the school administration. Informed consent was collected from the parents online. Students whose parents did not give consent or students who themselves refused to participate did not participate in the study. 


\subsection{Participants and Setting}

The general, compulsory, education system in Lithuania is of 12 years duration and consists of primary education, 4 years; basic (lower secondary) education, 6 years, and upper secondary education, 2 years. Grades $5-8$ represent the middle school and grades 9-12 (respectively I-IVth grades in gymnasiums) - high school. An assessment in grades 5-12 is criterion-referenced. A 1 to 10 marking system is used, with 10 as the highest and 4 as the lowest passing marks [25].

The study included 1483 school students across 5 th to 12 th grade from 11 to 19 years old. The average age was 14.62 (2.03) years. Among them, $56.9 \%$ were girls. The distribution of the number of students across 5 th to 12 th grades varied from $10.1 \%$ to $22.3 \%$. $50 \%$ were in grades 5th-8th and represented middle school, the rest $50 \%$ in grades 9 th to 12 th represented high school. In total, $72 \%$ of students live with both parents. A total of $12.7 \%$ also live with their siblings, $67.7 \%$ of participants represented region centers, and $32.3 \%$ represented rural areas in the county.

\subsection{Measurements}

\subsubsection{Academic Success}

Academic success was measured in terms of an actual average grade in the last semester or trimester for native and foreign languages, math, and history. Perceived academic outcomes ("Evaluate your learning outcomes at this time") and learning motivation ("Evaluate your willingness to learn right now") were indicated on a Likert scale from 1 - "Very poor" to 5-“Very good". Answers for the importance of being good at learning ("I need to study well"), learning satisfaction ("I am satisfied with my learning") were allocated on a scale from 1-“Never" to 4-"Always". Workload perception was also indicated by a single item ("How are you coping with the learning load?") with answers from 1-“Very heavy" to 5-“Not heavy at all". Finally, satisfaction with distance learning was measured by a single item ("How do you generally assess distance education as a form of student learning?") with answers from 1-“Very unsatisfied" to 5-“Very satisfied".

\subsubsection{Social Capital}

Social capital was measured by 16 items. The dimension of the social network was represented by one item (e.g., "Please rate how many people you are interacting with, that you could name as your friends?"). There were the following answers option: none, two-three, four-five, more than five. The communication aspect was identified by two items, indicating live and online communication with peers (e.g., Please identify how often you interact (live or online) with your classmates outside of class this semester?). Answers for the communication were from 1-"Never" to 5- "Several times a week and more". The relationship domain of school social capital was reflected across three social groups: parents, teachers, and peers. Answers were allocated on a Likert scale from 1- "Very bad" to 5 - "Very good". Trust was indicated by three items which represented general school trust, horizontal trust (trust in school mates), vertical trust (trust in teachers) (e.g., In your class, teachers and students trust each other). Reciprocity at school was identified by one item (Do you think students collaborate in your high school?). Finally, social support was measured by six items and represented the perception of support from each group within the school community: administration, class mentor, teachers, specialists facilitating the learning process (like a psychologist, social worker, speech therapist), peers, parents. The answers for the trust, reciprocity and social support items were allocated on a Likert scale from 1 - "Do not agree at all" to 5-“Totally agree".

The school social capital scale consisting of five items was developed based on the previous study among Lithuanian school-aged children [26]. The scale represents general school trust, vertical trust, horizontal trust, reciprocity, communication at school. The scale's compatibility factor in the current study is Cronbach $\alpha 0.879$.

The Social support scale was derived using the exploratory structural equation modeling (ESEM). Six items formed one factor. ESEM indicators confirmed the one factor 
structure (chi-square $(\chi 2)=39.57$; degrees of freedom $(\mathrm{df})=6$; root mean square error of approximation $(\mathrm{RMSEA})=0.061$; the comparative fit index $(\mathrm{CFI})=0.992$; Tucker-Lewis index $(\mathrm{TLI})=0.981$; the standardized root mean square residual $(\mathrm{SRMR})=0.017)$. The scale's compatibility factor is Cronbach $\alpha 0.864$.

Items on both school social capital and social support scales were combined into a mean score. Both scales in the current study represent the cumulative effect of social capital.

\subsubsection{Psychological Well-Being}

The WHO-5 is a short questionnaire consisting of 5 questions indicating the frequency of being active, vigorous, rested, relaxed, having interests, and being in good spirits, with the answers on the Likert scale from 0- "none of the time" to 5- "all of the time", which will tap into the subjective well-being and risk for depression of the respondents. The scale has adequate validity both as a screening tool for depression and as an outcome measure in clinical trials and has been applied successfully as a generic scale for well-being across a wide range of study fields [16].

Sociodemographic variables gender (1-“Girl", 2-"Boy") and age in full years were also assessed.

\subsection{Statistical Analysis}

Data were analyzed using SPSS 24.0 (SPSS Inc., Chicago, IL, USA) and MPLUS 8.4 software. Exploratory Structural Equation Modeling (ESEM) was performed to explore the structure of the social capital instrument. All continuous variables used in analyses met the assumptions of normality of the distribution after outliers exceeding three SDs were removed and scales' skewness and kurtosis were within the range- 1 and 1 . Descriptive statistics were calculated to determine the means and standard deviations (SDs) and frequencies of variables used in the study. The relationships between academic achievements and between social capital indicators were identified using the Pearson $r$ correlation coefficient. The predictive validity of social capital indicators for academic success was identified using the series of univariate and multivariate linear regression analyses. For mediation analysis, PROCESS version 3.5. [27] SPSS macro (Model 4) was employed, which tests direct and indirect effects in the mediation model $95 \%$ confidence intervals (CI) were estimated. An effect was considered significant when the CI did not include zero. Bootstrapping was set at 5000 samples. The completely standardized indirect effects were calculated as effect sizes for mediation [28]. Their values of $0.01,0.09$, and 0.25 represent small, medium, and large effect sizes, respectively [29]. Statistical significance was set at a $p$-value of less than 0.05 .

STROBE Statement—checklist guidelines were followed in organizing this paper.

\section{Results}

Study results (Table 1) of mean comparison reveal that perceived outcomes of academic success of middle and high school students differ, except for the importance of being good at learning, which is similar. All other outcomes including the average grade and perceived academic outcomes, learning motivation, satisfaction with distance learning, general learning satisfaction are higher and workload perception is lower among the middle school students in comparison with the high school students.

The results in Table 2 indicate that girls have more positive outcomes of academic success than boys in terms of average grade, perceived study results, the importance of being good at learning, and workload perception. Learning motivation, satisfaction with distance learning, and learning satisfaction are similar among boys and girls. 
Table 1. Comparison of academic success between younger and older schoolchildren $(n=1483)$.

\begin{tabular}{|c|c|c|c|c|}
\hline Academic Success Outcomes Indicators & Grades & Mean (SD) & Stjudent $\mathrm{t}$ & $p$ \\
\hline \multirow{2}{*}{$\begin{array}{c}\text { Average grades (native and foreign languages, } \\
\text { math and history) }\end{array}$} & 5-8 grades & $7.88(1.42)$ & \multirow[b]{2}{*}{5.102} & \multirow[b]{2}{*}{$<0.001$} \\
\hline & 9-12 grades & $7.51(1.31)$ & & \\
\hline \multirow{2}{*}{ Perceived academic outcomes } & $5-8$ grades & $3.61(0.95)$ & \multirow[b]{2}{*}{5.262} & \multirow[b]{2}{*}{$<0.001$} \\
\hline & $9-12$ grades & $3.35(0.97)$ & & \\
\hline \multirow{2}{*}{ The importance of being good at learning } & $5-8$ grades & $3.23(0.80)$ & \multirow{2}{*}{1.583} & \multirow{2}{*}{0.114} \\
\hline & $9-12$ grades & $3.17(0.80)$ & & \\
\hline \multirow{2}{*}{ Learning motivation } & $5-8$ grades & $3.06(1.14)$ & \multirow[b]{2}{*}{4.371} & \multirow[b]{2}{*}{$<0.001$} \\
\hline & $9-12$ grades & $2.81(1.09)$ & & \\
\hline \multirow{2}{*}{ Satisfaction with distance learning } & 5-8 grades & $3.44(1.04)$ & \multirow{2}{*}{6.999} & \multirow{2}{*}{$<0.001$} \\
\hline & $9-12$ grades & $3.04(1.12)$ & & \\
\hline \multirow{2}{*}{ Learning satisfaction } & $5-8$ grades & $2.68(0.76)$ & \multirow[b]{2}{*}{4.155} & \multirow{2}{*}{$<0.001$} \\
\hline & $9-12$ grades & $2.52(0.75)$ & & \\
\hline \multirow{2}{*}{ Workload perception } & $5-8$ grades & $2.75(0.82)$ & \multirow{2}{*}{4.660} & \multirow{2}{*}{$<0.001$} \\
\hline & $9-12$ grades & $2.54(0.85)$ & & \\
\hline
\end{tabular}

Note: MIN and MAX values for Average grades are 1 to 10 . MIN and MAX values for Perceived academic outcomes, learning motivation, Workload perception, and Satisfaction with distance learning were 1 to 5 . MIN and MAX values for Importance of being good at learning and Learning satisfaction were 1 to 4 .

Table 2. Comparison of academic success outcomes between girls and boys.

\begin{tabular}{|c|c|c|c|c|}
\hline Academic Success Outcomes Indicators & Gender & Mean (SD) & Stjudent $\mathrm{t}$ & $p$ \\
\hline \multirow{2}{*}{$\begin{array}{l}\text { Average grade (native and foreign languages, } \\
\text { math, and history) }\end{array}$} & Girls & $7.95(1.28)$ & \multirow{2}{*}{7.996} & \multirow{2}{*}{$<0.001$} \\
\hline & Boys & $7.36(1.44)$ & & \\
\hline \multirow{2}{*}{ Perceived academic outcomes } & Girls & $3.53(0.96)$ & \multirow[b]{2}{*}{2.409} & \multirow[b]{2}{*}{0.016} \\
\hline & Boys & $3.41(0.98)$ & & \\
\hline \multirow{2}{*}{ The importance of being good at learning } & Girls & $3.32(0.77)$ & \multirow{2}{*}{6.303} & \multirow{2}{*}{$<0.001$} \\
\hline & Boys & $3.05(0.83)$ & & \\
\hline \multirow{2}{*}{ Learning motivation } & Girls & $2.90(1.14)$ & \multirow{2}{*}{-1.331} & \multirow{2}{*}{0.183} \\
\hline & Boys & $2.98(1.09)$ & & \\
\hline \multirow{2}{*}{ Satisfaction with distance learning } & Girls & $3.21(1.05)$ & \multirow{2}{*}{-1.384} & \multirow{2}{*}{0.166} \\
\hline & Boys & $3.29(1.16)$ & & \\
\hline \multirow{2}{*}{ Learning satisfaction } & Girls & $2.57(0.74)$ & \multirow{2}{*}{-1.870} & \multirow{2}{*}{0.062} \\
\hline & Boys & $2.64(0.78)$ & & \\
\hline \multirow{2}{*}{ Workload perception } & Girls & $2.59(0.85)$ & \multirow{2}{*}{-3.124} & \multirow{2}{*}{0.002} \\
\hline & Boys & $2.72(0.82)$ & & \\
\hline
\end{tabular}

The results of the correlational analysis in Table 3 reveal that each social capital indicator is related at least at a weak level with any other one. Communication live and online indicators have mostly weak associations with other social capital indicators $(\mathrm{r}=$ from 0.069 to 0.314$)$. The strongest associations are observed between higher support from class mentors and support from teachers $(\mathrm{r}=0.745)$, support from school administration $(r=0.690)$. The latter is also related to higher support from school specialists $(r=0.650)$. The higher reciprocity at school is associated with higher horizontal trust $(\mathrm{r}=0.700)$ and vertical school trust $(r=0.633)$. The latter is strongly related to horizontal trust $(r=0.633)$ as well.

The results of another correlational analysis presented in Table 4 show that all academic success outcomes are interrelated. However, the strongest correlation is observed between perceived academic outcomes and learning satisfaction $(r=0.632)$. The higher the perceived academic outcomes, the higher learning satisfaction, and vice versa. An average actual grade and perceived learning results are also associated moderately $(\mathrm{r}=0.533)$. The higher the actual average grade, the higher are the perceived academic outcomes. The weakest, though positive associations are between the importance of being good at learning and satisfaction with distance learning as well as workload perception (both $r=0.097$ ) when the workload is perceived as less heavy. 
Table 3. The correlations between social capital indicators

\begin{tabular}{|c|c|c|c|c|c|c|c|c|c|c|c|c|c|c|c|}
\hline Social Capital Indicators & 2 & 3 & 4 & 5 & 6 & 7 & 8 & 9 & 10 & 11 & 12 & 13 & 14 & 15 & 16 \\
\hline 1. Social network (number of friends) & 0.308 ** & $0.264^{* * *}$ & 0.193 ** & $0.175 * *$ & $0.421 * *$ & $0.281 * *$ & $0.277^{* *}$ & $0.243 * *$ & $0.262 * *$ & 0.146 ** & $0.211^{* *}$ & $0.194 * *$ & $0.123 * *$ & $0.205 * *$ & $0.396^{* *}$ \\
\hline 2. Communication with friends (Live) & 1 & $0.289 * *$ & $0.136^{* *}$ & $0.088 * *$ & $0.243^{* *}$ & $0.158^{* *}$ & $0.173 * *$ & 0.143 ** & $0.154^{* *}$ & $0.077^{* *}$ & $0.114^{* *}$ & $0.092 * *$ & $0.071 * *$ & $0.150 * *$ & $0.272 * *$ \\
\hline 3. Communication with friends (Online) & & 1 & $0.125^{* *}$ & $0.157^{* *}$ & $0.307^{* *}$ & $0.116^{* *}$ & $0.177^{* *}$ & $0.126^{* *}$ & 0.173 ** & $0.087^{* *}$ & 0.142 ** & $0.115^{* *}$ & 0.069 ** & 0.168 ** & $0.314 * *$ \\
\hline 4. Relationship with parents & & & 1 & $0.518^{* *}$ & $0.409 * *$ & $0.309 * *$ & $0.244^{* *}$ & 0.226 ** & $0.226^{* *}$ & $0.247^{* *}$ & $0.339 * *$ & $.0315^{* *}$ & $0.221 * *$ & $0.544^{* *}$ & $0.260 * *$ \\
\hline 6. Relationship with peers & & & & & 1 & $0.357^{* *}$ & 0.406 ** & 0.334 ** & 0.413 ** & $0.201 * *$ & $0.299 * *$ & $0.277^{* *}$ & 0.195 ** & $0.332 * *$ & $0.514^{* *}$ \\
\hline 7. School trust (general) & & & & & & 1 & 0.551 ** & 0.637 ** & 0.532 ** & $0.485^{* *}$ & $0.488^{* *}$ & $0.496^{* *}$ & $0.366^{* *}$ & $0.349^{* *}$ & $0.444^{* *}$ \\
\hline 8. Reciprocity at school & & & & & & & 1 & $0.633^{* *}$ & 0.700 ** & 0.293 ** & $0.326^{* *}$ & $0.349^{* *}$ & $0.242 * *$ & 0.305 ** & $0.492 * *$ \\
\hline 9. Vertical school trust & & & & & & & & 1 & $0.633 * *$ & 0.391 ** & $0.404^{* *}$ & $0.478^{* *}$ & $0.323 * *$ & $0.314 * *$ & 0.440 ** \\
\hline 10. Horizontal school trust & & & & & & & & & 1 & 0.270 ** & $0.334^{* *}$ & $0.338^{* *}$ & $0.237 * *$ & 0.296 ** & $0.476^{* *}$ \\
\hline 12. Support from class mentors & & & & & & & & & & & 1 & $0.745^{* *}$ & $0.541^{* *}$ & $0.556^{* *}$ & $0.475 * *$ \\
\hline 13. Support from teachers & & & & & & & & & & & & 1 & 0.621 ** & 0.498 ** & $0.458 * *$ \\
\hline 14. Support from school specialists & & & & & & & & & & & & & 1 & $0.367^{* *}$ & $0.349^{* *}$ \\
\hline 15. Support from parents & & & & & & & & & & & & & & 1 & $0.475^{* *}$ \\
\hline 16. Support from classmates & & & & & & & & & & & & & & & 1 \\
\hline
\end{tabular}


Table 4. The correlations between indicators of academic success.

\begin{tabular}{|c|c|c|c|c|c|c|}
\hline $\begin{array}{c}\text { Academic Success Outcomes } \\
\text { Indicators }\end{array}$ & 2 & 3 & 4 & 5 & 6 & 7 \\
\hline 1. Average grade & $0.533^{* *}$ & $0.321 * *$ & $0.134^{* *}$ & $0.126 * *$ & $0.377^{* *}$ & $0.195^{* *}$ \\
\hline 2. Perceived academic outcomes & 1 & $0.339 * *$ & $0.437 * *$ & $0.325 * *$ & $0.632 * *$ & $0.318^{* *}$ \\
\hline $\begin{array}{c}\text { 3. The importance of being good } \\
\text { at learning }\end{array}$ & & 1 & $0.419 * *$ & $0.097 * *$ & $0.332 * *$ & $0.097 * *$ \\
\hline 4. Learning motivation & & & 1 & $0.173^{* *}$ & $0.373 * *$ & $0.305^{* *}$ \\
\hline 5. Satisfaction with distance learning & & & & 1 & $0.272^{* *}$ & $0.242^{* *}$ \\
\hline 6. Learning satisfaction & & & & & 1 & $0.319 * *$ \\
\hline 7. Workload perception & & & & & & 1 \\
\hline
\end{tabular}

The results of the Linear regression analyses presented in Table 5 for each academic success outcome reveal that among covariates, younger age is specifically related to higher academic success across all learning indicators. Boys have lower average grades than girls and have a lower perception of the importance of being good at learning. Moreover, boys have higher satisfaction with their learning, distant learning processes and are more at ease with their workload perception. However, both covariates explained just a small percent of the variance in learning outcomes indicators $(2-3 \%)$.

Table 5. Social capital predictors for academic success outcomes and psychological well-being.

\begin{tabular}{|c|c|c|c|c|c|c|c|c|}
\hline $\begin{array}{l}\text { Indicators of School } \\
\text { Social Capital }\end{array}$ & $\begin{array}{c}\text { Average } \\
\text { Grades } \\
\text { (Native and } \\
\text { Foreign } \\
\text { Languages, } \\
\text { Math and } \\
\text { History) }\end{array}$ & $\begin{array}{l}\text { Perceived } \\
\text { Academic } \\
\text { Outcomes }\end{array}$ & $\begin{array}{c}\text { The } \\
\text { Importance } \\
\text { of Being } \\
\text { Good at } \\
\text { Learning }\end{array}$ & $\begin{array}{l}\text { Learning } \\
\text { Motivation }\end{array}$ & $\begin{array}{l}\text { Satisfaction } \\
\text { with } \\
\text { Distance } \\
\text { Learning }\end{array}$ & $\begin{array}{l}\text { Learning } \\
\text { Satisfaction }\end{array}$ & $\begin{array}{l}\text { Workload } \\
\text { Perception }\end{array}$ & $\begin{array}{l}\text { Psychological } \\
\text { Well-Being }\end{array}$ \\
\hline Covariates & \multicolumn{8}{|c|}{ Std. Beta } \\
\hline Gender (boys) & $-0.197^{* * *}$ & -0.038 & $-0.166^{* * *}$ & 0.038 & $0.053 *$ & $0.066^{* *}$ & $0.070 * *$ & $0.199 * * *$ \\
\hline Age & $-0.173^{* * *}$ & $-0.113^{* * *}$ & $-0.051^{*}$ & $-0.107^{* * *}$ & $-0.143^{* *}$ & $-0.113^{* * *}$ & $-0.117 * * *$ & $-0.087^{* * *}$ \\
\hline$\Delta \mathrm{R}^{2}$ (for covariates) & $0.08^{* * *}$ & $0.03^{* * *}$ & $0.03^{* * *}$ & $0.02 * * *$ & $0.03^{* * *}$ & $0.02 * * *$ & $0.03^{* * *}$ & $0.07^{* * *}$ \\
\hline \multicolumn{9}{|l|}{ Social capital indicators } \\
\hline $\begin{array}{c}\text { Number of friends (Social } \\
\text { network) }\end{array}$ & $0.080 * *$ & 0.031 & 0.049 & -0.034 & -0.034 & -0.013 & 0.045 & $0.063 *$ \\
\hline $\begin{array}{l}\text { Communication with } \\
\text { friends (Live) }\end{array}$ & $-0.080^{* *}$ & -0.012 & 0.016 & 0.039 & -0.042 & -0.049 & -0.017 & $0.085^{* *}$ \\
\hline $\begin{array}{l}\text { Communication with } \\
\text { friends (Online) }\end{array}$ & $0.140^{* * *}$ & $0.075 * *$ & $0.069 * *$ & 0.004 & $0.100 * * *$ & $0.098 * * *$ & 0.024 & -0.022 \\
\hline Relationship with parents & $-0.105^{* *}$ & $0.088 * *$ & 0.020 & $0.095 * *$ & $0.100 * *$ & 0.058 & 0.033 & $0.184^{* * *}$ \\
\hline $\begin{array}{l}\text { Relationship with } \\
\text { teachers }\end{array}$ & $0.236^{* * *}$ & $0.439 * * *$ & $0.209 * * *$ & $0.323^{* * *}$ & $0.116^{* *}$ & $0.272 * * *$ & $0.181^{* * *}$ & $0.085^{* *}$ \\
\hline Relationship with peers & 0.024 & 0.038 & 0.014 & 0.013 & 0.008 & 0.048 & -0.028 & 0.039 \\
\hline School trust (general) & 0.029 & -0.023 & 0.024 & -0.041 & -0.072 & 0.051 & -0.009 & $0.082 *$ \\
\hline Reciprocity at school & 0.017 & -0.006 & 0.010 & -0.005 & 0.034 & 0.016 & $0.076^{*}$ & -0.033 \\
\hline Vertical school trust & $-0.161^{* * *}$ & $-0.086 *$ & -0.016 & $0.082 *$ & -0.008 & -0.066 & 0.022 & $0.081 *$ \\
\hline Horizontal school trust & -0.015 & 0.006 & 0.022 & 0.051 & -0.005 & 0.003 & -0.046 & 0.015 \\
\hline $\begin{array}{l}\text { Support from school } \\
\text { administration }\end{array}$ & -0.062 & -0.015 & 0.032 & $0.071 *$ & -0.023 & -0.041 & 0.006 & $0.135^{* * *}$ \\
\hline $\begin{array}{l}\text { Support from class } \\
\text { mentors }\end{array}$ & 0.029 & 0.034 & 0.071 & -0.028 & 0.033 & 0.039 & -0.055 & -0.041 \\
\hline Support from teachers & 0.006 & 0.003 & 0.076 & $0.132 * *$ & 0.061 & $0.096 *$ & $0.149 * *$ & 0.044 \\
\hline $\begin{array}{l}\text { Support from school } \\
\text { specialists }\end{array}$ & -0.026 & 0.001 & $-0.088^{* *}$ & -0.059 & 0.010 & 0.012 & 0.006 & -0.007 \\
\hline Support from parents & $0.086^{*}$ & 0.038 & $0.102^{* *}$ & 0.020 & -0.044 & 0.007 & -0.020 & -0.025 \\
\hline Support from classmates & $0.102 * *$ & 0.049 & -0.052 & -0.025 & 0.025 & 0.036 & 0.042 & 0.011 \\
\hline$\Delta \mathrm{R}^{2}$ (for social capital) & $0.12^{* * *}$ & $0.30 * * *$ & $0.16^{* * *}$ & $0.25^{* * *}$ & $0.070^{*}$ & $0.20 * * *$ & $0.10^{* * *}$ & $0.20 * * *$ \\
\hline
\end{tabular}

Note: ${ }^{*}-p<0.05{ }^{* *}-p<0.01{ }^{* * *}-p<0.001$.

Better relationship with teachers is consistently is related to learning outcomes across all its indicators. The social network in terms of the number of friends among other learning outcomes indicators is related only to the average of actual grades. The more friends schoolchildren have, the better are their average grades. Better relationships with parents 
have an adverse association with the average actual grade but are linked to better-perceived learning results, higher learning motivation, and higher satisfaction with distant learning. Online-based communication with friends is related to the higher average grade, perceived learning results, the importance of being good at learning, learning satisfaction, and satisfaction of distance learning. While live communication with friends is adversely related to the average grade, indicating that more live contacts predict worse actual learning results. Higher vertical school trust- the indicator for trust between schoolchildren and teachersis associated with lower average grades and perceived learning results, but higher learning motivation. Perceived support of school administration is only related to higher learning motivation. Support from teachers is associated with higher learning satisfaction, learning motivation, and lower perception of workload. Moreover, a lower perception of workload is predicted by higher reciprocity at school between classmates. Support from school specialists, like psychologists or social workers is linked to lower perceived importance of being good at learning. Meanwhile, parental support is associated with higher perceived importance of being good at learning and higher average grade. Similarly, higher average grades are related to support from classmates. General school trust, relationship with peers, horizontal trust (trust among classmates), and support from class mentors are not among predictors of learning outcomes. Social capital indicators explained from $7 \%$ (Satisfaction with distance learning) to $30 \%$ (Perceived academic outcomes) of variance in learning outcomes.

The direct effects of social support and school social capital (combined as scale variables) for psychological well-being were positive (std. Coeff. $=0.326$ and 0.260 , respectively) Mediation analysis performed with PROCESS by Hayes revealed that the effects of social support and school social capital for academic success outcomes are mediated by psychological well-being. However, the positive effects of mediation varied from small (for perceived academic outcomes, the importance of being good at learning, learning satisfaction, and workload perception) to medium (for learning motivation) (Table 6). The mediation effects for average grades were negative as psychological well-being is negatively related to average grades (std. Coeff. $=-0.085)$.

Table 6. Mediation effects of psychological well-being (PWB) in the relationship of social support and academic successs (DLO).

\begin{tabular}{|c|c|c|c|c|c|c|c|c|}
\hline \multirow[t]{3}{*}{ Academic Success } & \multicolumn{4}{|c|}{ Indirect Effects of Social Support for DLO via PWB } & \multicolumn{4}{|c|}{$\begin{array}{l}\text { Indirect Effects of School Social Capital for DLO via } \\
\text { PWB }\end{array}$} \\
\hline & \multicolumn{2}{|c|}{ Indirect effect } & \multicolumn{2}{|r|}{ CSIE } & \multicolumn{2}{|c|}{ Indirect effect } & \multicolumn{2}{|r|}{ CSIE } \\
\hline & $\beta$ & $95 \% \mathrm{CI}$ & $\beta$ & $95 \%$ CI & $\beta$ & $95 \% \mathrm{CI}$ & $\beta$ & $95 \%$ CI \\
\hline Average grade & -0.05 & {$[-0.081--0.014]$} & -0.03 & {$[-0.049-0.010]$} & -0.05 & {$[-0.090--0.018]$} & -0.03 & {$[-0.050--0.010]$} \\
\hline Perceived academic outcomes & 0.06 & {$[0.033-0.085]$} & 0.05 & {$[0.027-0.068]$} & 0.06 & {$[0.033-0.085]$} & 0.05 & {$[0.027-0.068]$} \\
\hline $\begin{array}{l}\text { The importance of being } \\
\text { good at learning }\end{array}$ & 0.04 & {$[0.019-0.057]$} & 0.04 & {$[0.020-0.061]$} & 0.04 & {$[0.024-0.066]$} & 0.04 & {$[0.023-0.064]$} \\
\hline Learning motivation & 0.15 & {$[0.111-0.183]$} & 0.11 & [0.086-0.139] & 0.16 & [0.125-0.205] & 0.11 & [0.089-0.143] \\
\hline $\begin{array}{l}\text { Satisfaction with } \\
\text { distance learning }\end{array}$ & 0.04 & {$[0.013-0.066]$} & 0.03 & {$[0.010-0.051]$} & 0.05 & {$[0.021-0.080]$} & 0.04 & [0.015-0.057] \\
\hline Learning satisfaction & 0.06 & {$[0.042-0.082]$} & 0.07 & [0.047-0.091] & 0.07 & [0.048-0.093] & 0.07 & [0.050-0.096] \\
\hline Workload perception & 0.08 & [0.056-0.101] & 0.08 & [0.057-0.102] & 0.09 & [0.061-0.111] & 0.08 & [0.057-0.102] \\
\hline
\end{tabular}

\section{Discussion}

The current study aimed to identify important social capital factors within different contexts of a school community that might be associated with academic success in the context of distance learning during the COVID-19 pandemic. Our study indicates that the relationship with teachers is the strongest and the most important predictor of academic success across its different indicators: average grade, perceived academic outcomes, the importance of being good at learning, learning motivation, satisfaction with distance learning, learning satisfaction, workload perception. Moreover, greater vertical trust, which represents trust in teachers, predicted higher learning motivation. In turn, the authors 
point out that motivated students use higher cognitive processes in learning the material, so that they will absorb the material better [18].

The authors explain that social capital associated with schools can reflect community ties, but typically refer to the relationships that children form with school teachers that can facilitate educational outcomes. However, the authors of the study which was aimed to compare the importance of family and school social capital for academic achievements found that family social capital was more important than school social capital in the United States [30]. Moreover, a pre-pandemic study in Norway found that both parent-student and teacher-student relationships, but not teacher help are significant predictors of student academic achievements [31]. These different results might be explained by differences in the societies in which the population was investigated. For instance, Bassani's study revealed that school social capital in Japan was a stronger predictor for academic success in comparison with family social capital than in the United States, though both were significant predictors [32]. In any case, parents and schools share the responsibility of educating children, and social capital derived from different contexts complement each other and this illustrates the saying that "it takes a village to raise a child". Social capital is usually created in multiple contexts and interacts in the process of producing outcomes. For example, capital developed in families interacts with capital developed at school to produce academic success, so more positive school social environments compensate the negative effects of destructive relationships within the family or vice versa. Beyond this interaction, the results of hierarchical regression in the current study also revealed that parental support and relationships with parents were important positive predictors for certain academic success indicators, namely the average grade, perceived academic achievements, the importance of being good at learning, learning motivation, satisfaction with distance learning. Thus, family and school social capital may work both together and independently to affect students' academic success.

In addition to family and teachers, other factors at school appeared to be important for academic success. For instance, the current study identified that social networksupportive social connections, and support from classmates predicted better average grades, reciprocity at school predicted lower workload perception and communication with friends online besides better average grade predicted higher perceived academic outcomes, the importance of being good at learning, satisfaction with distance learning and general learning satisfaction. However, the relationship with peers and horizontal school trust, which represents trust in schoolmates, controlling for sociodemographic and other social capital variables did not emerge as the significant predictors. Other studies also suggest that investments in peer social capital offer relatively little in return to contribute to academic success. Neither of the studies performed in Norway or Romania revealed the significant effect of peer-derived social capital for academic achievements [22].

The results of other studies imply that the COVID-19 pandemic fostered educational inequality along the achievement dimension [31]. Nevertheless, the results of the current study highlight the impact teachers can make in lessening the inequalities in education. Despite the argument of some authors, that children's learning outcomes mostly depend on the family environment [33], parental education [34], but not on schools, the current study confirmed that teachers are also very important agents in students' life and might contribute to the more successful educational outcomes which play a role as a social elevator reducing the gaps occurring because of family socioeconomic status.

The results also point out the emergent importance of the relationship with teachers in the context of distance learning, given that the results of the previous study in the same country, before the COVID-19 pandemic, in 2018, did not highlight vertical trust, which reflects trust in teachers, as an important predictor of academic achievement. Instead, family social support, the horizontal trust which represents trust in peers, and reciprocity at school were significant for academic achievements in the earlier report [35]. Some other studies before the pandemic also explained teachers' contribution to students' academic success in terms of teachers' personal traits, organizational commitment, pedagogical 
content knowledge, or the passion for education [36]. The results of the current study led to the assumption that the context of distance learning, its related physical isolation, and distance highlighted the importance of social connections for learning and learning outcomes. Although social capital from parents and peers also matters, the relationship with teachers emerges as the main and the most important source in supporting positive attitude and outcomes in learning.

Along with social capital, psychological well-being is considered a precondition for several outcomes, including academic success $[35,37,38]$, however research reports conflicting results on this relationship. Studies reporting positive association were primarily cross-sectional, focused on relational aspects of wellbeing and younger children [39]. The current study, though also cross-sectional covered a larger age interval of schoolchildren and was focused on a broader set of academic success indicators. Yet, the current study indicated that being positively related and predicted by school social capital and social support, psychological well-being mediated the effect of the latter two for perceived academic outcomes, the importance of being good at learning, learning satisfaction, and workload perception and for learning motivation. The review of studies on the relationship of psychological well-being and academic success also found that the link is strengthened by social relations [40]. This might be also explained by Self-determination theory whose main postulate states that the motivation for learning, and learning itself, is enhanced when a supportive environment satisfies a student's psychological needs for autonomy, competence, and relatedness [21].

The analysis of controlling factors in the relationship between social capital and academic success revealed the negative effect of older age for the full set of studied academic success indicators. While other studies are in line with these results and confirm that older (senior) students have worse academic achievements [41], other studies explain that along with negative age-academic success link, age is also negatively related to child-parent interaction, but older student's age helps build social capital outside the home (e.g., good student-teacher relationship, which has a positive impact on achievement [42]. While boys are more satisfied with distance learning and learning in general, girls have higher average grades and a higher perception of the importance of being good at learning. These results confirm the results of the previous study in Lithuania, which revealed that girls report higher grade point averages [35].

\section{Limitations}

One of the main limitations of the study is its observational, cross-sectional nature. The data used here does not allow for a unique impact of social capital for academic success particularly during distance learning as the results might also reflect the general relationships as they used to be before the pandemic. Thus, the data on how both social capital and academic success might shift from pre-pandemic to a pandemic is beyond the scope of this paper. However, the results of this study still definitely show that the absence of physical contact with the teachers, even assuming it has not increased, is still very important.

\section{Conclusions}

Middle school students and girls are more successful in an academic field than their older counterparts from high school and boys. The relationships with teachers emerged as a steady predictor in a range of academic success outcomes. Moreover, during the period of distance learning, online communication with friends and parental support contributed to academic success. The effect of social capital on academic success is mediated by psychological well-being psychological well-being.

In the context of the disruption to education that occurred during the COVID pandemic, these findings appear to support the importance of close and trusting social ties, especially between students and their teachers as well as parents for better learning outcomes. Given that psychological wellbeing is a key factor for many positive life outcomes 
including academic success, it becomes especially important in times of crisis to maintain mental health, and strengthening social ties should be a principal focus. The results of the current study may aid policymakers and practitioners in developing intervention policies and practices that focus resources where they will have the greatest benefit. Older and male students should be specially addressed. Thus, by enhancing social capital at schools, the social and organizational environment for students could be improved, which has a positive impact on students' psychological well-being and leads to students' academic success. The results would appear to support the proposition that the school is sustainable if it is developing as an ecosystem, not solely focused on academic outcomes.

Policymakers are encouraged to develop and implement social capital strengthening programs at the national, municipal, and local community levels, involving representatives of the public sector, non-governmental organizations, members of schools and local communities, experts with unique experience and representing different social, interests of economic, cultural, religious, and linguistic groups. Policymakers and school leaders should integrally strengthen the social capital at school along with students' achievements, and monitor both. School leaders are encouraged to develop guidelines to strengthen the development of social capital in the classroom, support for the students and parents, and promote a culture of classroom ecosystem development. This study is the prerequisite for further research on the influence of various factors on students' socio emotional, psychological, and cultural wellbeing and academic outcomes in mixed (online, offline) educational settings. Intervention, longitudinal and experimental studies are needed to identify the effect size of the impact of social capital on the students' achievements.

Author Contributions: Conceptualization, I.K. and B.M.; methodology, I.K., B.M., A.E., R.J. and S.G.; software, I.E., E.B., S.S.; validation, R.B., R.J., V.B. and J.B.-K.; formal analysis, B.M., I.K. and A.E.; investigation, D.Z. and S.S.; resources, D.Z., S.S. and R.J.; data curation, R.B.; writing-original draft preparation, B.M. and A.E.; writing—review and editing, J.B.-K. and S.G.; visualization, E.S.-R.; supervision, I.K.; project administration, B.M.; funding acquisition, B.M., A.E., R.J., S.G., R.B., V.B., D.Z., S.S. and I.K. All authors have read and agreed to the published version of the manuscript.

Funding: This research was funded by the Research Council of Lithuania, grant number No. S-DNR20-8. Brigita Mieziene, Arunas Emeljanovas, Roma Jusiene, Sigita Girdzijauskiene, Virginija Budiene, Rima Breidokiene, Stanislav Sabaliauskas, Dainius Zvirdauskas, and Ichiro Kawachi received that grant. The funders had no role in the study design, data collection and analysis, the decision to publish, or the preparation of the manuscript.

Institutional Review Board Statement: The study was conducted in accordance with the Declaration of Helsinki, and approved by the Ethics Committee of Vilnius University (protocol No. 66, 26 May 2021).

Informed Consent Statement: Informed consent was obtained from all subjects involved in the study.

Data Availability Statement: The data presented in this study are available on request from the corresponding author.

Acknowledgments: The authors would like to thank Rasa Jauniskiene and Renata Gaudinskaite for their huge support in data collection.

Conflicts of Interest: The authors declare no conflict of interest. The funders had no role in the design of the study; in the collection, analyses, or interpretation of data; in the writing of the manuscript, or in the decision to publish the results.

\section{References}

1. Esposito, S.; Principi, N. School closure during the coronavirus disease 2019 (COVID-19) pandemic: An effective intervention at the global level? JAMA Pediatr. 2020, 174, 921-922. [CrossRef]

2. Petretto, D.R.; Masala, I.; Masala, C. School Closure and Children in the Outbreak of COVID-19. Clin. Pract. Epidemiol. Ment. Health 2020, 16, 189. [CrossRef] [PubMed]

3. Kuhfeld, M.; Soland, J.; Tarasawa, B.; Johnson, A.; Ruzek, E.; Liu, J. Projecting the potential impact of COVID-19 school closures on academic achievement. Educ. Res. 2020, 49, 549-565. [CrossRef] 
4. Kousky, C. Impacts of natural disasters on children. Future Child. 2016, 26, 73-92. Available online: https:/ / eric.ed.gov / ?id=EJ1 101425 (accessed on 22 December 2021). [CrossRef]

5. Dorn, E.; Hancock, B.; Sarakatsannis, J.; Viruleg, E. COVID-19 and student learning in the United States: The hurt could last a lifetime. McKinsey Co. 2020, 1, 1-9. Available online: https://www.apucis.com/frontend-assets/porto/initial-reports/COVID19-and-student-learning-in-the-United-States-FINAL.pdf.pagespeed.ce.VHbS948yF4.pdf (accessed on 22 December 2021).

6. Eyles, A.; Gibbons, S.; Montebruno Bondi, P. Covid-19 school shutdowns: What will they do to our children's education? Lond. Sch. Econ. Polit. Sci. 2020, 1, 2-8. Available online: http://eprints.lse.ac.uk/104675/ (accessed on 22 December 2021).

7. Murayama, H.; Fujiwara, Y.; Kawachi, I. Social Capital and Health: A Review of Prospective Multilevel Studies. J. Epidemiol. 2012, 22, 179-187. [CrossRef]

8. Reimers, F.; Schleicher, A. Schooling disrupted, schooling rethought. How the COVID-19 Pandemic is Changing Education. OECD 2020, 14, 3-61. Available online: https:/ /www.educatemagis.org/wp-content/uploads/documents/2020/07/document.pdf (accessed on 22 December 2021).

9. Gromada, A.; Rees, G.; Chzhen, Y. Worlds of Influence: Understanding what shapes child well-being in rich countries. In The Innocenti Report Card 16; UNICEF Office of Research: Innocenti/Florence, Italy, 2020. Available online: https://www.unicef.org/ media/77571/file/Worlds-of-Influence-understanding-what-shapes-child-well-being-in-rich-countries-2020.pdf (accessed on 22 December 2021).

10. Valstybinio Audito Ataskaita: Ar Pokyčiai Švietime Lemia Geresnius Mokiniu Pasiekimus. 2020 m. Rugsejo 14 d. Nr. VAE-11. National Audit Report: Do Changes in Education Lead to Better Pupils' Achievements. 14 of September 2021. Nr. VAE-11. Available online: https:/ / www.lrs.lt/sip/getfile?guid=2656f505-0ebf-4767-874a-35410be32bbe (accessed on 22 December 2021).

11. Lu, J.; Yang, J.; Yu, C.S. Is social capital effective for online learning? Inform. Manag. 2013, 50, 507-522. [CrossRef]

12. Sheingold, B.H.; Hahn, J.A.; Hofmeyer, A. Hiding in Plain Sight: Building Community Social Capital in Distance Education Graduate Programs. Contemp. Issues Educ. Res. (CIER) 2013, 6, 265. [CrossRef]

13. Novak, D.; Emeljanovas, A.; Miežiene, B.; Štefan, L.; Kawachi, I. How different contexts of social capital are associated with self-rated health among Lithuanian high-school students. Glob. Health Act. 2018, 11, 1477470. [CrossRef]

14. Novak, D.; Popović, S.; Emeljanovas, A.; Miežiene, B.; Krističević, T. Are Family, Neighborhood and School Social Capital Associated with Psychological Distress Among Lithuanian High-School Students? A Cross-Sectional Study. Int. J. Sport Manag. Recreat. Tour. 2016, 23, 75. [CrossRef]

15. Oppong Asante, K. Social support and the psychological wellbeing of people living with HIV/AIDS in Ghana. Afr. J. Psychiatry 2012, 15, 340-345. [CrossRef]

16. Topp, C.W.; Østergaard, S.D.; Søndergaard, S.; Bech, P. The WHO-5 Well-Being Index: A systematic review of the literature. Psychother. Psychosom. 2015, 84, 167-176. [CrossRef]

17. Huppert, F.A. Psychological well-being: Evidence regarding its causes and consequences. Appl. Psychol. Health Well-Being 2009, 1, 137-164. [CrossRef]

18. Rehman, A.U.; Bhuttah, T.M.; You, X. Linking burnout to psychological well-being: The mediating role of social support and learning motivation. Psychol. Res. Behav. Manag. 2020, 13, 545. [CrossRef] [PubMed]

19. World Health Organization. Available online: https://www.who.int/news-room/fact-sheets/detail/adolescent-mental-health (accessed on 22 December 2021).

20. Ryan, R.M.; Deci, E.L. On happiness and human potentials: A review of research on hedonic and eudaimonic well-being. Ann. Rev. Psychol. 2001, 52, 141-166. [CrossRef] [PubMed]

21. Ryan, R.; Deci, E. Self-Determination Theory: Basic Psychological Needs in Motivation, Development, and Wellness; The Guilford Press: New York, NY, USA; London, UK, 2017; pp. 3-724.

22. Huang, L.; Dămean, D.; Cairns, D. Social capital and student achievement: Exploring the influence of social relationships on school success in Norway and Romania. Creat. Educ. 2015, 6, 1638-1649. [CrossRef]

23. Etikan, I.; Bala, K. Sampling and sampling methods. Biom. Biostat. Int. J. 2017, 5, 00149. [CrossRef]

24. Oficialios Statistikos Portalas. Official Statistics Portal. Available online: https://osp.stat.gov.lt/infografikas22 (accessed on 31 January 2022).

25. Centre for Quality Assessment in Higher Education. Available online: https://www.skvc.lt/default/en/education-in-lithuania/ general (accessed on 31 January 2022).

26. Mieziene, B.; Emeljanovas, A.; Tilindiene, I.; Tumynaite, L.; Trinkuniene, L.; Kawachi, I. The Direct and Indirect Relationships of Environmental, Interpersonal and Personal Factors with High School Students Physical Activity: An Ecological Approach. Int. J. Environ. Res. Public Health 2021, 18, 874. [CrossRef]

27. Hayes, A.F. Partial, conditional, and moderated mediation: Quantification, inference, and interpretation. Commun. Monogr. 2018, 85, 4-40. [CrossRef]

28. Preacher, K.J.; Kelley, K. Effect size measures for mediation models: Quantitative strategies for communicating indirect effects. Psychol. Methods 2011, 16, 93-115. [CrossRef]

29. Cohen, J.A. Power primer. Psychol. Bull. 1992, 112, 155-159. [CrossRef] [PubMed]

30. Dufur, M.J.; Parcel, T.L.; Troutman, K.P. Does capital at home matter more than capital at school? Social capital effects on academic achievement. Res. Soc. Stratif. Mobil. 2013, 31, 1-21. [CrossRef] 
31. Grewenig, E.; Lergetporer, P.; Werner, K.; Woessmann, L.; Zierow, L. COVID-19 and educational inequality: How school closures affect low- and high-achieving students. Eur. Econ. Rev. 2021, 140, 103920. [CrossRef]

32. Bassani, C. A test of social capital theory outside of the American context: Family and school social capital and youths' math scores in Canada, Japan, and the United States. Int. J. Educ. Res. 2006, 45, 380-403. [CrossRef]

33. Bilsteen, J.F.; Ekstrøm, C.T.; Børch, K.; Nybo Andersen, A.M. The role of parental education on the relationship between gestational age and school outcomes. Pediatr. Perinat. Epidemiol. 2021, 35, 726-735. [CrossRef]

34. Hart, B.; Risley, T.R. Meaningful Differences in the Everyday Experience of Young American Children; Paul, H., Ed.; Brookes Publishing Company: Baltimore, MD, USA, 1995.

35. Novak, D.; Emeljanovas, A.; Miežienè, B.; Antala, B.; Štefan, L.; Kawachi, I. Is social capital associated with academic achievement in Lithuanian high-school students? A population-based study. Monten. J. Sports Sci. Med. 2018, 7, 29-35. [CrossRef]

36. Alemdar, M.; Anılan, H. Reflection of social capital in educational processes: Emotional literacy and emotional labor context. Asia Pac. Educ. Rev. 2021, 1-17. [CrossRef]

37. Lyons, M.D.; Huebner, E.S. Academic characteristics of early adolescents with higher levels of life satisfaction. Appl. Res. Qual. Life 2016, 11, 757-771. [CrossRef]

38. Simovska, V.; Nordin, L.L.; Madsen, K.D. Health promotion in Danish schools: Local priorities, policies and practices. Health Promot. Int. 2016, 31, 480-489. [CrossRef] [PubMed]

39. Amholt, T.T.; Dammeyer, J.; Carter, R.; Niclasen, J. Psychological well-being and academic achievement among school-aged children: A systematic review. Child Ind. Res. 2020, 10, 1523-1548. [CrossRef]

40. Le, B.M.; Impett, E.A.; Lemay, E.P.J.; Muise, A.; Tskhay, K.O. Communal motivation and well-being in interpersonal relationships: An integrative review and meta-analysis. Psychol. Bull. 2018, 144, 1-25. [CrossRef] [PubMed]

41. Momanyi, J.M.; Too, J.; Simiyu, C. Effect of students' age on academic motivation and academic performance among high school students in Kenya. Asian J. Educ. E-Learn. 2015, 3, 337-342. Available online: https:/ / www.ajouronline.com/index.php/AJEEL/ article/view/3130 (accessed on 22 December 2021).

42. Huang, L. Social capital and student achievement in Norwegian secondary schools. Learn. Individ. Differ. 2009, 19, 320-325. [CrossRef] 